\title{
Seasonal seawater Al dynamics and response to short-term perturbations in the Gulf of Aqaba, northern Red Sea
}

\author{
T. BENALTABET ${ }^{1,2, *}$, G. LAPID ${ }^{1,2}$, A. TORFSTEIN ${ }^{1,2}$ \\ ${ }^{1}$ Institute of Earth Sciences, Hebrew University of Jerusalem, \\ Jerusalem, Israel \\ (*correspondence: tal.benaltabet@mail.huji.ac.il) \\ ${ }^{2}$ Interuniversity Institute for Marine Sciences, Eilat, Israel
}

Seawater Aluminium $(\mathrm{Al})$ is a widely used proxy for atmospheric dust input to surface waters and recycling of terrigenous material in open oceans. However, the impact of short-term environmental events, such as dust storms and sediment resuspension, on the oceanic water column composition is poorly constrained due to the typically low sampling temporal resolution in open ocean environments. The Gulf of Aqaba (GoA), northern Red Sea, is a deep oligotrophic water body, which undergoes seasonal cycles of water column stratification and deep mixing. In addition, the GoA is surrounded by hyper-arid deserts with no major tributaries, and hence receives limited terrigenous input, except for frequent dust storms and rare flash floods.

Here, we report a highly resolved time series of vertical profiles of dissolved Al concentrations sampled during 2017 -2018, with an emphasis on daily resolution sampling across dust storm events. We further evaluate the results in the context of the water column configuration, nutrient contents, and settling particle fluxes.

Dissolved Al concentrations range between 33 - $90 \mathrm{nmol}$ $\mathrm{kg}^{-1}$. Upper mixed layer $\mathrm{Al}$ inventories presents a decrease of $12-20 \%$ in concentrations in response to dust storms, as dissolved $\mathrm{Al}$ is scavenged by settling dust particles. On the other hand, following a rare wet dust deposition event, $\mathrm{Al}$ inventories in the mixed layer increased by $35 \%$, reflecting the enhanced leaching of mineral $\mathrm{Al}$ into the dissolved phase by rainwater. Elevated deep $\mathrm{Al}$ concentrations in winter are driven by an independently observed discrete surge in resuspended particulate material, suggesting that sediment resuspension is a prominent source of deep $\mathrm{Al}$, with a residence time of at least 11 weeks for resuspended $\mathrm{Al}$.

Dissolved $\mathrm{Al}$ and Si display a positive linear correlation, though the relative excess of $\mathrm{Al}$ changes seasonally, suggesting differential controls of scavenging and biological uptake on the two elements. 